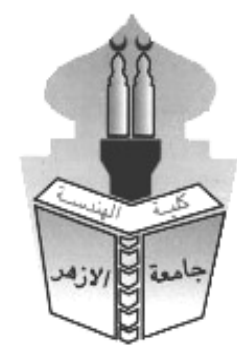

\title{
FATIGUE LIFE PREDICTION OF UN-NOTCHED ROUND SPECIMENS BASED ON CRACKING SIMULATION
}

\author{
M. M. Farag*, R. M. El-Kady, and M. M. I. Hammouda
}

Mechanical Engineering Department, Faculty of Engineering, Al-Azhar University, Nasr

ABSTRACT

City, Cairo, Egypt

*Corresponding Author E-mail:: eng_mahfarag2010@azhar.edu.eg

This work presents a cracking damage model to assess fatigue lives of un-notched round specimens in axial stresses due to constant and variable amplitude loading. The model numerically simulates collective behavior of growing short fatigue surface cracks originating from the surface roughness of specimens made of a two-phase alloy. The specimen roughness is assumed resembling micro cracks of different sizes and locations along the minimum specimen circumference. Material grains of different phases, sizes and strengths are randomly distributed over that circumference. To verify the model, this work utilized published experimental data on round specimens made of ferritic-pearlitic steel and tested in push-pull constant and variable amplitude loading with (a) two-step high-low and low-high sequences, (b) repeated two-step loading blocks. To simulate laboratory testing, different specimens were randomly configured and virtually tested. Comparison of the experimental results and corresponding predictions shows the validity of the model.

\section{KEYWORDS: Surface Roughness; Cracking Simulation; Fatigue Life Assessment; Variable Amplitude Loading; Cumulative Fatigue Damage.}

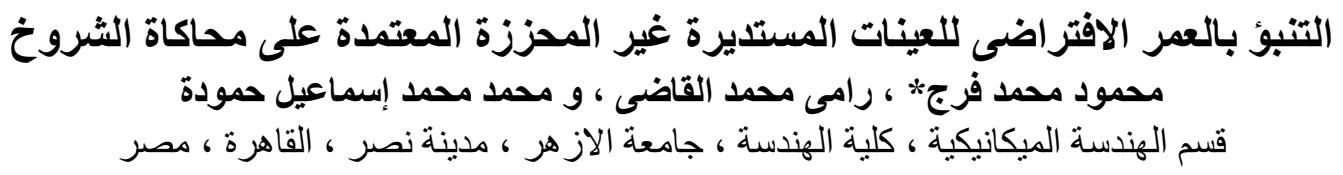

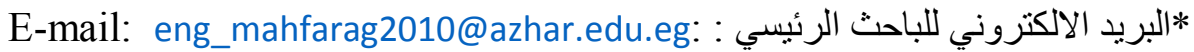

يقدم العمل الحالى محاكاة للشروخ المعتمدة على العمر الافتر اضى للأحمال الثابتة والأحمال المتغيرة. النموذج يعمل محاكاة النقاة

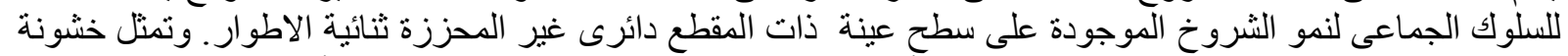

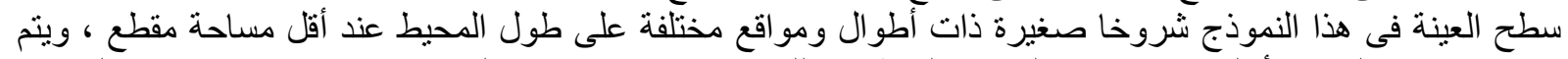

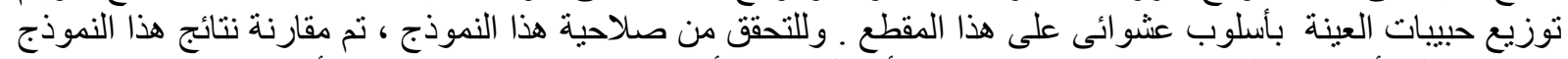

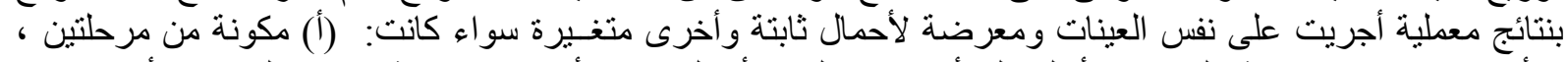

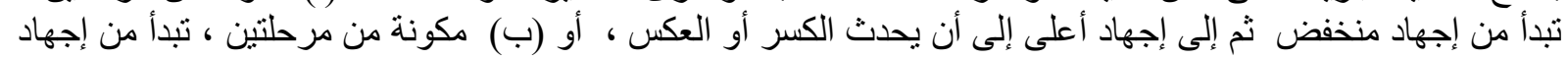

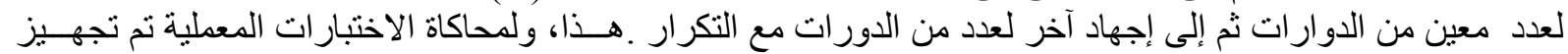

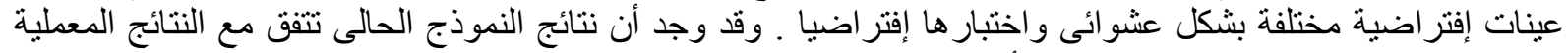
المنشورة. علاوة على ذللك ، قد تم دراسة تأثير خشونة السطح وقطر العينة و الإجهاد المتوسط على عمر الكلل .

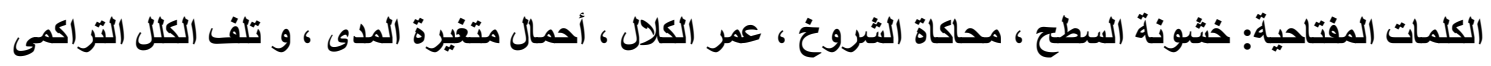




\section{INTRODUCTION}

Most engineering components fail due to fatigue loads which vary with time in terms of its type, magnitude and direction [1]. Loading history may show those variations either separately or in combination $[1,2]$. Numerous published experimental, theoretical, analytical and numerical research papers have focused on the special case of constant amplitude loads (CAL) $[1,3]$. Fatigue researchers devoted also their attention to variable loading (VL) for its significance and relevance to in-service situations [3-9]. To be either experimentally investigated or theoretically analyzed, some cases were simplified to repeated blocks of loading cycles. With the objective of understanding the effect of VL, two-step loading of either the same type or different types with different sequences have been experimentally and theoretically invoked [9-27].

Life assessment is mostly the end target of the researches on fatigue of engineering materials and structures [28]. Materials may be metallic and further assumed homogeneous and isotropic or not. In-service structures can be dissembled into free body components which are geometrically and kinetically idealized for further investigation. Test specimens may be appropriately designed to represent such components and suit laboratory testing. An hour glass solid cylindrical specimen is usually used for fatigue testing in push-pull cyclic loading. That specimen, in this case, typically breaks at its minimum cross section [4, 5]. Fatigue life assessment of engineering materials and components under CAL utilizes relevant reliable $\mathrm{S} / \mathrm{N}$ endurance data experimentally determined through extensive testing to evaluate their dependency on some material, geometrical, surface and environmental parameters [1, 3, 28]. Fatigue cracks initiate from the most favorable surface or subsurface sites [29-31], e.g. geometrical imperfections, favorably oriented grains, non-metallic inclusions or brittle precipitates. The growth of such cracks may lead to fracture. In un-notched components fatigue cracks can originate from the roughness of their surface $[32,33]$ with initial sizes comparable to local micro-structural features rendering the LEFM characterization of crack growth invalid $[34,35]$. Elastic-plastic fracture mechanics has been used to characterize the behavior of such short cracks [36, 37].

Generally, fatigue damage accumulates with applied cycles even when the stress levels are below the fatigue limit for most of the loading history [2]. In the case of variable amplitude loading (VAL), fatigue life assessment relies on the full $\mathrm{S} / \mathrm{N}$ curve of the considered material which is established through CAL testing [3-28]. The Palmgren-Miner linear damage rule was the first in that direction [9,10]. That rule has the shortcoming of ignoring interaction and sequence effects [11-19] in addition to its inability to recognize damages taking place below the material's fatigue limit. As a result, many different fatigue damage models have been proposed to remedy those deficiencies. Some models, e.g. [38], require the evaluation of some material-dependent parameters through extensive testing which may not be available to a design engineer, causing some difficulties in fatigue life estimation by those models. Other recent models do not need such extensive testing. An example is the damage curve approach due to Gao et al. [39] which is based on a similar work by Manson et al. [40]. Shang and Yao [41] proposed another simple continuum fatigue damage model which takes into account the effect of mean stress.

Mesmacque et al. [42] developed a damage rule which utilized only the full S-N curve of the material and the von Mises stress as a damage indicator. Siriwardane et al. [43] applied that rule to estimate the remaining fatigue life of railway bridges and a significant deviation was reported between predicted and in-service lives and, thus, they developed [44] a similar rule using the plastic meso-strain as the damage indicator instead. Other models applied the concept of iso-damage curves in a nonlinear damage model utilizing the material full $\mathrm{S} / \mathrm{N}$ curve to analyze fatigue lifetime under VL [27, 45]. A bi-linear cumulative damage model [46] is an example of such an approach. This model was used to predict residual lifetimes for cases of two-step loading with high-low (H-L) and low-high $(\mathrm{L}-\mathrm{H})$ sequences. Other nonlinear cumulative fatigue damage models [21, 28, 47-53] were developed and used to show their capabilities to predict the fatigue lifetime of notched and un-notched specimens due to VL. 
Some researchers considered the accumulation of fatigue damage by deformation processes, e.g. [5]. Other cumulative fatigue damage models were based on ductility exhaust and crack propagation, e.g. [54]. The concept that fatigue cracking damage accumulates with applied cycles was invoked in the literature both experimentally and theoretically. Miller and Zachariah [55] and Miller and Ibrahim [56] used an exponential cumulative fatigue damage law to demarcate the fatigue crack initiation and short crack propagation in un-notched round specimens in torsion and push-pull. They (1) used two different laws for the fatigue growth during the two phases of initiation and short crack propagation and (2) assumed the roughness of the specimen surface resembling micro cracks.

Existing cumulative fatigue damage models based on cracking consider a single or isolated dominant crack. This inevitably over-estimates the fatigue lifetime of the specimen as the coalescence of interacting in-plane and out-of-plane cracks shortens the time to failure [5761]. Further, the individual short crack behavior imposes great difficulty in regard to modeling the very early stages of crack growth as individual cracks are susceptible to large changes in growth rate depending on their exact lengths and position relative to micro-structural barriers, the features of the random distribution of the grains along with other mechanical and metallurgical effects.

This work presents a cracking damage model to assess fatigue lives of un-notched round specimens in axial stresses due to constant and variable amplitude loading. The model numerically simulates collective behavior of growing short fatigue surface cracks originating from the surface roughness of specimens made of a two-phase alloy.

\section{RELEVANT PREVIOUS WORK}

The present work is based on the results of two previous works [62, 63]. The first work developed a dynamic two-dimensional elastic-plastic FE model to simulate cyclic plastic deformation accommodated at the tip of an edge crack of length $l$ at the mid-section of an axially loaded plate [62]. The second identified the factors controlling such deformation for both long and physical short mode I fatigue cracks [63]. Some fracture mechanics parameters were presented against remotely applied stresses and material flow properties. Parameters such as the extents of the monotonic and cyclic plastic zones, respectively $\Delta_{m}$ and $\Delta_{c}$, developed at the tip of a crack artificially advancing in the plane strain state were given in addition to the corresponding average shear strain within $\Delta_{m}, \gamma$, and its range within $\Delta_{c}, \Delta \gamma$. The extents of $\Delta_{m}$ and $\Delta_{c}$ were fitted to Eqs. 1 and 2

$$
\begin{aligned}
& \left(\frac{l}{\Delta_{m}}\right)^{1.07}=\frac{0.73}{\operatorname{lngec} \frac{W}{2 \sigma_{y}}}-1.736 \\
& \left(\frac{l}{\Delta_{v}}\right)^{0.9}=\frac{1.89}{\ln 5 e c \frac{\pi \Delta S}{2 \Delta \sigma_{y e}}}-4.272
\end{aligned}
$$

The extent of the maximum and cyclic crack tip opening displacement (CTOD), respectively $\delta$ and $\Delta \delta$, could, thus, be fitted as presented in Fig. 1.

A crack tip deformation parameter $(C T D P),=\delta^{0.46} \Delta \delta^{0.54}$, has been devised and succeeded to correlate growth rates both of long cracks in some fatigue problems [62] and of physical short cracks [63]. Hammouda and Sallam [62] utilized this parameter to correlate experimental FCG rates of geometrically different specimens made of three materials tested at different stress ranges and ratios as depicted in Fig. 2 which shows four lines fitting the experimental data. The present model invokes those power relations to have the growth rate of the present cracks.

\section{THE PRESENT MODEL}

An un-notched cylindrical solid specimen; see Fig. 3(a), is considered. The specimen is made of an alloy having the two phases 1 and 2. Here, $\sigma_{y}$ and $\sigma_{y g}$ are respectively the average monotonic and cyclic yield stress of the alloy. The phases 1 and 2 have volumetric percentage $N_{1}$ and $N_{2}$. The grain size of each phase has an average value $d$ with a certain standard deviation. Figure $3(\mathrm{~b})$ shows $n$ material grains arranged on the specimen surface. The volumetric phase percentage and the average grain size enable the estimation of the number of grains of each phase $M 1$ and $M 2$ such that the sum of their sizes $d_{g}$ equals to the specimen 
minimum circumference (SMC) which has a diameter D. The total number of surface grains is $n=M 1+M 2$. The average values of the monotonic and cyclic yield stress of phase $k$ are respectively $\sigma_{y k}$ and $\sigma_{y c k}$ both with a certain standard deviation.

Multi coplanar micro cracks are assumed existing along the SMC. The roughness of the specimen surface resembles those micro cracks of different sizes and locations. The grain $j$ is assumed having a surface central crack of a length $l_{z}=l_{j}$. Figure 3(c) presents a schematic example of such a crack which has the two surface tips B1 and B3 and subtends an angle $\theta$ at the specimen center, Fig. 3(d). A crack is defined as a material separation having two tips at the surface. Amongst the measures used to characterize the roughness, the values of maximum peak-to-valley height and mean surface roughness may dictate an average initial crack depth with its standard deviation. The crack front in the material depth is B1-B2-B3, Fig. 3(d). The crack front is assumed having the geometry of a circular arc. The grain crack is short enough to have its front center close to the specimen surface such that the crack depth $\cong 0.5 l$. Generally, $l$ calculates the corresponding cracked area $A$. Consequently, $A_{C}=\sum A_{r}$ is the sum of the cracked areas and $A_{S,}=\pi D^{2} / 4-A_{C}$ is the supporting cross sectional area.

The four variables $d_{g}, l$ and the monotonic and cyclic yield stresses, respectively, $\sigma_{y}$ and $\sigma_{y o}$ are assumed normally distributed with values assigned at random amongst the grains with no bias. Here, the value of any of those variables assigned to a grain is $V_{j}$. The average and standard deviation values of those variables give their maximum and minimum values as $V_{\max }$ and $V_{\min }$ respectively. Then, $V_{j}=V_{\min }+f_{j}\left(V_{\max }-V_{\min }\right)$ where $f_{j}$ is a random real number between 0 and 1 set by a pseudorandom generator. Having the grains of the two phases with their four variables assigned, they are sequentially numbered. The grains are, then, selected one by one at random and juxtaposed accordingly along the SMC as shown in Fig. 3(b). In Fig. 3(b) point $\mathrm{O}$ is an origin arbitrarily chosen along the SMC used to calculate the coordinates of the boundaries of a grain and the two tips of a crack with the determination of the grain in which each tip exists.

The test starts with a specimen having an initial configuration as described above. A cyclic axial load with an amplitude $P$ and a stress ratio $R$ is applied such that the initial testing stress amplitude is $\sigma_{0}=4 P / \pi D^{2}$ whilst the current applied stress amplitude is $\sigma=P / A_{S}$.

As a consequence of load application, some grains experience plastic deformation. The model considers a grain plastically deformed when $\sigma$ becomes greater than its yield stress. The following analysis is applied on the monotonic and cyclic plastic deformation generated ahead of each crack tip. Figure 4(a), shows schematically two opposing tips, $T_{1}$ and $T_{2}$, of two adjacent cracks, $C_{1}$ and $C_{2}$, located in two neighboring grains, $G_{1}$ and $G_{2}$, with their boundary $B$. The extent of the plastic zone ahead of $T_{1}$ is $\Delta_{1}$. The distance between the two tips is $\zeta$.

The extent of the plastic zone ahead of $T_{1}$ given by Eqs.1 and 2, h, is carefully calculated to ensure its validity. The present model uses the yield stress of the grain to which the furthest element of $h$ belongs. The yield stress of $G_{1}$ is, first, substituted. Should the resulting extent of $h \leq \zeta_{1}$, then, $h$ is a valid value. Otherwise, $h$ is recalculated by making use of the yield stress of $G_{2}$. If, in this case, $\mathrm{h} \leq \zeta_{1}$, then, $B$ arrests the plastic zone and, hence, $\mathrm{h}=\zeta_{1}$. The term $\zeta_{1}$ refers to the distance between $T_{1}$ and $B$.

Another relevant term, q, is defined, here, as the plasticity extent within the grains located ahead of $T_{1}$. The value of $\mathrm{q}=0$ in the case of having (1) both $G_{1}$ and $G_{2}$ behaving elastically and (2) $G_{\mathbf{1}}$ elastically behaving and $G_{2}$ plastically behaving with $\mathrm{h} \leq \zeta_{1}$. Otherwise, $\mathrm{q}$ is given 
by the distance between $T_{1}$ and the left boundary of the next grain behaving elastically ahead of that tip. The extent $s_{1}$ is, then, either h or q whichever is greater.

Figure 4(b) shows the above situation applied on $T_{2}$. Similarly, the extent $S_{2}$ is defined for $T_{2}$. Should both $s_{1}$ and $s_{2}$ be less than $\zeta$ and $s_{1}+s_{2}$ be greater than $\zeta$, then $\Delta_{1}=\zeta$. Otherwise $\Delta_{1}=S_{1}$. Thus, $\Delta_{1}$ can (1) be within $G_{1}$ with an extent $\Delta_{1}$; (2) be arrested at $B$, i.e. $\Delta_{1}=\zeta_{1}$; (3) cross $B$ to have $\zeta \geq \Delta_{1}>\zeta_{1}$; (4) or cross some grains ahead of $T_{1}$. Having one of those possibilities depends principally on the current applied stress, the length of the two cracks, the size of the two grains and the yield stress of each grain.

As described in the previous section, the current cracking configuration, the applied load and the extents of the monotonic and cyclic plastic zones ahead of $T_{1}$ calculate the extent of the corresponding CTDP. Figure 2, then, calculates the advance rate of $T_{1}$.

All existing tips are subject to the above calculation steps. An increment of load cycles is adjusted and, then, allowed to capture the earliest event out of (1) a maximum crack tip advance of $0.1 \mu m,(2)$ a maximum approach of each opposing two tips of $0.1 \mu m$ and (3) the next merge of two approaching tips. The increment of load cycles required for merging those two tips is given by $\frac{\zeta}{a_{1}+a_{2}}$ where $d_{1}$ and $d_{2}$ are the advance rate of the two tips. This entails updating the coordinates of the tips and their locations within the surface grains. A loop of computations is terminated with this cracking configuration.

A software is developed in Visual Basic to follow and repeat the above calculations for further computational loops. A flow chart of the developed program is presented in Fig. 5. After $\mathrm{N}$ load cycles, $\boldsymbol{A}_{C}$ increases, $\boldsymbol{A}_{S}$ decreases and $\sigma$ increases. Further, the two opposing tips of some adjacent cracks approach leading to a possible decrease in the extent of the plastic zones ahead of the tips of some cracks. Thus, the tip of a crack has the possibility of either advancing or stop propagating. Hence, the opposing tips of two adjacent cracks either stop their advance at a distance or merge to form one crack.

The propagation activity of the existing cracks results in two possible scenarios. Should $\sigma_{o}>$ the material's fatigue limit, $\sigma_{F}$, the specimen breaks after the application of $N_{f}$ load cycles. That occurs when $A_{S}$ becomes unable to withstand the applied load. The second scenario takes place if $\sigma_{0} \leq \sigma_{F}$. In this case, all existing cracks become non-propagating after $N_{p}$ load cycles and, hence, the specimen is unbroken after $N$ load cycles $>10^{7}$.

To simulate laboratory testing, a specimen is randomly configured and, then, virtually tested at a given stress level. The above model enables the fatigue life assessment of the tested specimen.

\section{APPLICATION}

The created software was utilized to simulate laboratory experiments on $0.4 \% \mathrm{C}$ steel round solid specimens tested in fully reversed direct stresses at $34 \mathrm{~Hz}$ in air. In that application, the specimens had a minimum diameter $=7.3 \mathrm{~mm}$. The alloy was composed of ferrite and pearlite phases with respective volumetric ratio 70:30. The mean grain size was $36 \mu \mathrm{m}$ for both phases with $\mathrm{SD}=13 \mu \mathrm{m}$. The estimated surface 445 ferrite grains and 191 pearlite grains were randomly arranged along the SMC. The grain sizes and the lengths of the initially existing cracks, $l_{o}$, were normally distributed. The maximum $l_{o}$ value was $0.1 \mu \mathrm{m}$. The material had an ultimate tensile stress $\sigma_{u}=580 \mathrm{MPa}$ and an average monotonic yield stress $\sigma_{y}=400 \mathrm{MPa}$. The mixture rule concluded average values for $\sigma_{y}$ of each phase, i.e. $\sigma_{y_{1}}=275.9 \mathrm{MPa}$ for the ferrite grains and $\sigma_{y 2}=689.7$ for the pearlite grains. Search in the literature showed 
considerable variations in $\sigma_{y}$ of both phases. Values up to $\sigma_{y 1}=312 \mathrm{MPa}$ and $\sigma_{y 2}=1020$ $\mathrm{MPa}$ could be found. Thus, SD values of $35.9 \mathrm{MPa}$ and $331 \mathrm{MPa}$ were invoked for $\sigma_{y}$ of the ferrite and pearlite grains respectively. Variations in $\sigma_{y}$ of the grains of each phase were assumed randomly distributed between the minimum and maximum value of the corresponding phase. The cyclic yield stress of a grain was assumed $=0.6$ its monotonic yield stress.

The program was run to trace possible events of fatigue growth behavior of the existing surface cracks due to the application of a constant stress amplitude $\sigma_{0}$ with a stress ratio $\mathrm{R}=$ 1. Different specimens were randomly configured, virtually tested at different $\sigma_{0}$ and their $S / N$ curve was constructed. A single experimental endurance data point was utilized for adjustment and a factor of 0.012 was concluded to modify the value of $\frac{d a}{d N}$ extracted from Fig. 2.

The validity of the model was, further, checked against its recognition of the effect of surface roughness, specimen size and mean stress on $N_{f}$.

The model has been developed to simulate cumulative fatigue cracking damage due to the loading configurations listed in Table 1 and as experimentally carried out by De Los Rios et al. [4] with the same testing conditions described above.

Table 1(a) lists two sets of experimental parameters corresponding to two-step cumulative fatigue damage. Those tests were simulated as follows. From the simulation-based $\mathrm{S} / \mathrm{N}$ curve, the average number of cycles to fracture at the two stress amplitudes $\sigma_{01}$ and $\sigma_{02}$ were $N_{f_{1}}$ and $N_{f_{n}}$ respectively. A specimen was randomly configured and virtually tested at $\sigma_{o 1}$ for $N_{1}<N_{f 1}$, cycles. The stress amplitude $\sigma_{o 2}$ was, then, applied for $N_{2}$ cycles when fracture took place. Further, the test was repeated with specimens having the same configuration but for different values of $\frac{N_{1}}{N_{f_{1}}}$. Those two stress levels were utilized to execute corresponding virtual tests with $\mathrm{L}-\mathrm{H}$ and $\mathrm{H}-\mathrm{L}$ sequences.

In repeated application of two-step loading blocks, a virtual specimen was continuously subjected to identical blocks of loading till fracture took place. The six two-step block loading tests listed in Table 1(b) were simulated. The parameters of a test were (1) the stress amplitude $\sigma_{o 1}$ of the first loading block which was applied for $N_{1}$ cycles and (2) the stress amplitude $\sigma_{o 2}$ of the second loading block which had $N_{2}$ cycles. A randomly configured specimen was virtually tested for $N_{1}$ cycles at $\sigma_{01}$ and, then, for $N_{2}$ cycles at $\sigma_{02}$. That loading configuration was repeated till the fracture of the specimen.

\section{RESULTS AND DISCUSSION}

Many metallurgical and mechanical factors, manufacturing operations, surface treatments, cleaning and handling have strong influences on fatigue crack initiation. Because of all those factors, it is very difficult to predict the minimum size and location of a naturally initiated fatigue crack. Miller [37] has suggested that micro cracks should be considered existing in all structures. Miller and Zachariah [55] and Miller and Ibrahim [56] assumed the roughness of the specimen surface resembling micro cracks in their studies to demarcate the fatigue crack initiation and short crack propagation in un-notched round specimens in torsion and pushpull. They used two different laws for the fatigue growth during the two phases of initiation and short crack propagation. The evidence of microstructure evolution of crack initiation was not presented in their analysis and also in the present model. It is extremely difficult to numerically simulate slip concentration and the subsequent formation of persistent slip bands that eventually become cracks. 
The inability of the SIF to correlate the behavior of short cracks at high stresses is due to the fact that LEFM is only valid under SSY conditions. Most crack tips at all the loads in the present simulation for most of the grains, particularly the ferrite grains and the pearlite grains with relatively low yield stresses, are plastically deformed both monotonically and cyclically. Further, some short cracks in the elastically deformed grains propagate at relatively high stresses compared to their yield stresses. A parameter which has a prime attention in elasticplastic fracture mechanics is the CTOD [64]. That concept is based on the assumption that where significant plasticity occurs, the intense deformation adjacent to the crack tip primarily controls the fatigue process. The separation of the crack faces is a measure of such a deformation field.

The present model utilized a correlation between FCG rates and a devised CTDP $=\delta^{0.46} \Delta \delta^{0.5}$ for both long and short cracks. Numerical results due to Hammouda et. al. [63] were best fitted when $\frac{\delta}{i}$ was plotted as shown in Fig. 1(a) against $\gamma^{0.1177}\left[1+2.6\left(\frac{2}{\Delta_{m}}\right)^{0.735}\right]^{-1.3}=\beta$. For relatively long cracks at low stresses, i.e. the case of small scale yielding (SSY), $\frac{\delta}{l}$ is directly related to $\beta$. In this case, $\gamma$ is constant, $1 \ll 2.6\left(\frac{2}{\Delta_{m}}\right)^{0.735}$ and thus, $\beta$ is approximately proportional to $\left(\frac{\Delta_{m}}{l}\right)^{0.96} \cong \frac{\Delta_{m}}{l}$, i.e. $\delta \sim \Delta_{m}$ as given by LEFM. On the other hand, the term between square brackets tends to 1 for short cracks at high stresses to have $\frac{\delta}{i}$ as a function of $\gamma$ only. This means that the square brackets term is responsible for the fatigue behavior of long cracks whilst the shear strain dictates the behavior of short cracks. The behavior of $\frac{\Delta d}{l}$ shown in Fig. 1(b) as a function of $\Delta \gamma^{0.77}\left[1+2.6\left(\frac{l}{\Delta s}\right)^{0.657}\right]^{-1.3}$ can be discussed within a similar framework. The shear strain term represents the driving force for crack tip deformation (CTD) which increases exponentially with the applied stress after yielding. The square brackets term may be viewed as the resistance to the development of such deformation which continuously increases as the size of the crack tip plastically deformed zone decreases relative to the crack size, approaching the condition of SSY. In other words, short cracks have less resistance to CTD. Thus, at the same SIF level the propagation of short cracks should be faster than that of long cracks.

For simplicity, the present model assumes coplanar cracks against experimental observations $[65,66]$. Efforts may be exercised in future works to consider the present model with noncoplanar cracks. The model further assumes no interaction between the two opposing tips of adjacent cracks when the two tips are approaching each other, for example, the phenomenon reported by Seah and Qian [67]. Through detailed finite element numerical investigations, Seah and Qian [67] examined the effect on the near-tip stress field caused by the presence of two adjacent coplanar cracks in 2D and 3D plate models under elastic-plastic large deformation due to tensile loads normal to the surfaces of the cracks. That study covered the effect of material hardening properties, the effect of crack spacing and the relative crack sizing on the computed crack driving force and the near-tip stress field. Their results supported the existence of an "over constraining" effect caused by the presence of an adjacent crack tip except for the crack front locations near the free surface. The presence of a nearby free surface forces the stress redistribution to occur in nearby front materials away from the crack tip, leading to nearly no crack interaction effect near the free surface. This justifies the assumption invoked in the present simulation.

Figure 6(a,b) presents examples of $A_{C}$ against $N$ assessed by the present model at different constant $\sigma_{o}$ values. The total length of cracks $L_{T}$ existing on the specimen surface is related to 
$A_{C}$ and, thus, both $A_{C}$ and $L_{T}$ are expected to behave similarly. From Fig. 7, the material's fatigue limit $\sigma_{F}$ numerically obtained by the present simulation is $166 \mathrm{MPa}$ compared with the experimental value of $275 \mathrm{MPa}$. Invariably, $A_{c}$ starts initially to increase with a relatively high rate which continuously decreases with the increase in $A_{C}$. At $\sigma_{\theta} \leq \sigma_{f}$, the computation is terminated after $N_{p}$ loading cycles when all existing cracks become non-propagating. At $\sigma_{o}>\sigma_{F}$, there is a continuous rate increase beyond the minimum rate. Such behavior can be found in the literature but in terms of crack lengths rather than cracked area [4, 68]. In the present work, failure is invariably assumed taking place when $\sigma_{\max }=\sigma_{U}$. On the HCF range where $\sigma_{o}<575 \mathrm{MPa}$ and $N_{f}>5000$ cycles, see the numerical data point with the cross in Fig. 7, all the surface cracks merged to form an approximate circular supporting area with no fracture, i.e. $\sigma_{\max }<\sigma_{\cup}$, having a cracked area $A_{C} \approx 0.37 \mathrm{~mm}^{2}$ and a radial crack depth $\approx 17 \mu \mathrm{m} \approx$ one grain size. In that range the results of the present work shows that the change in $\sigma$ is not appreciable in the course of the applied load cycles. To achieve the fracture of the specimen, the computation related to the developed software is terminated and the next computational procedures follow. Equations 1 and 2, Fig. 1 and the relevant relations [63] were utilized to incrementally estimate the CTDP for the ring crack and, then, to calculate its radial growth rate by making use of Fig. 2. The remaining life was determined when $\sigma_{\max }=\sigma_{U}$. The average mechanical properties of the ferrite phase were invoked for those calculations since cracks are expected to avoid facing obstacles of hard phase grains by propagating around them through the surrounding softer grains. All the runs documented in the present work estimated remaining lives $<2 \%$ of the computational termination life which was, thus, assumed, here, equal to $N_{f}$.

On the LCF range where $\sigma_{0}<575 \mathrm{MPa}$ and $N_{f}>5000$ cycles, see Fig. 7, the specimens break with some surface cracks unmerged when $\sigma_{\max }=\sigma_{U}$. The specimens in the present work are virtually tested under load control. In the course of load cycling, $A_{\varepsilon}$ appreciably increases and hence $A_{S}$ appreciably decreases leading to a noticeable increase in the applied stress. This means that in the present LCF range the specimen under the present load control is subjected to a continuously increasing stress, i.e. the test is neither stress controlled nor strain controlled. This explains the deviation of the proposed approach from the experimental data which appears on the LCF range in Fig. 7(a).

At fracture in the HCF regime, the present model produces a final circular separating area at the specimen core. The model considers growing fatigue micro cracks, $\leq 0.1 \mu \mathrm{m}$, originating only from the roughness of a round specimen surface. Other possible surface defects, such as inclusions and pores [1], are not considered and the load is assumed axially applied with no eccentricity. With this view, material elements at different surface sites are expected to behave equally.

At all constant stress levels, Fig. 6(a, b) exhibits retardation of $\frac{d A_{C}}{d N}$ in the course of periods while some advancing tips are either approaching or arrested at the boundaries of pearlite hard grains. Further, coalescence of adjacent cracks is the main reason of having the sudden increases in $A_{C}$ shown in Fig. 6(a, b). Such observations are common in relevant published experimental works $[1,65,69,70]$.

The fatigue limit of a material is defined as the maximum stress range below which there is no fracture after the application of an infinite number of loading cycles. According to this definition, $\sigma_{F}=166 \mathrm{MPa}$ for the present material. At $\sigma_{o}=166 \mathrm{MPa}$, relevant present data show that one of the two tips of an active dominant crack is unable to cross a hard pearlite grain. The stress amplitude needs to be $167 \mathrm{MPa}$ to overcome that obstacle at $N$ much longer 
than $10^{7}$ cycles. In practice, a fatigue test is terminated when $N$ reaches about $10^{7}$ cycles with no fracture of the specimen and the fatigue limit is accordingly assessed. Thus, experimentally determined fatigue limit $\sigma_{F}$ of the present material is $275 \mathrm{MPa}$ greater than present numerically obtained value of $166 \mathrm{MPa}$. As experimentally found in the literature [4], the present results show clearly that there are some micro cracking activities at and below the fatigue limit. For those stress amplitudes, all the existing cracks become non-propagating at a number of cycles increasing with $\sigma_{0}$. Further, $A_{C}$ of those cracks increases.

The present simulation demonstrated some surface cracking activities. An example follows. Figure 8 shows the development of a surface crack about $0.702 \mathrm{~mm}$ long after the application of 28650 loading cycles at $\sigma_{o}=390 \mathrm{MPa}$ whose $N_{f}=182000$ cycles. The site of that activity is shown at the top right corner of Fig. 8. That crack is the result of the growth and, consequently, the coalescence of smaller cracks within 19 surface grains 18 of which are ferrite with one pearlite grain. The pearlite grain clearly resists the development of that crack. The vertical line drawn on Fig. 8 at $N=4000$ cycles indicates the existence of three cracks at the site. Moving that line along the horizontal axis shows the progressive activities of the two tips of each crack with $N$. The simulation process sets initial cracks in the corresponding grains, so that they eventually develop into a major crack in the specimen as demonstrated by that example.

The open circles in Fig. 7(a) show the present assessment of the material endurance data which were produced by making use of different specimens with surface grains randomly configured in terms of their phase, size, and strength and included crack size. The solid points represent relevant experimental results available for the same material [4]. The prediction of the present model is in general agreement with experiment. The present model can predict endurances in the regimes of both HCF and LCF, of course, under load control. This can be attributed to the ability of the invoked CTDP in correlating FCG rates to link the behavior of high stress short cracks and low stress long cracks [62]. For endurances in the HCF regime, the data are fitted, see Fig. 7(b), to the following Basquin [71] relation

$\Delta \sigma_{o} N_{f}^{0.119}=3251.8$

The exponent of 0.119 is in agreement with similar values for the same material in the literature [58]. For endurances shorter than $10^{4}, N_{f}$ decreases with an increase in relevant $\sigma_{o}$ which asymptotically approaches $\sigma_{U}$.

For more verification, Fig. 9 presents the prediction of the present model for the well-known effect on fatigue lifetime of (a) surface roughness, (b) specimen size and (c-e) mean stress. Figure 9(a) compares endurance data predicted at three $\sigma_{o}$ levels for two values of surface roughness representing starting crack sizes of $0.1 \mu \mathrm{m}$ and $0.2 \mu \mathrm{m}$. As the surface roughness increases, $N_{f}$ decreases [1]. This means that surface roughness information is important in correctly capturing the fatigue limit of a material and a practicing engineer will need to repeat the present approach for the same material with different surface treatment. Figure 9(b) shows that an increase in the specimen diameter form $7.3 \mathrm{~mm}$ to $12 \mathrm{~mm}$ causes a corresponding decrease in $N_{f}$ [1]. More surface cracks are involved in damaging the larger specimen. The present model considers possible differences in stress ratio against the present application which implements the case of push-pull loading. Thus, two examples follow to show that the present model identifies the effect of stress ratio. The effect of increasing the mean stress on $N_{f}$ is demonstrated in Fig. 9(c) with the same $\sigma_{o}$ and the varying $\sigma_{\max }$ whilst in Fig. 9(d) with the same $\sigma_{\max }$ and varying $\sigma_{o}$. The endurance decreases with increasing the mean stress when comparison is based on the same $\sigma_{o}$ [1]. The reverse effect is displayed in Fig. 9(d) in the 
case of comparing $N_{f}$ on the basis of the same $\sigma_{\max }$ [1]. It is clear that the present model recognizes the effect of the above three variables on fatigue lives. A further support is given in Fig. 9(e) which presents the so-called $10^{7}$-based Soderberg diagram as produced by the present simulation for the considered material.

In Fig. 6(c), $A_{C}$ is plotted against $N$ as a result of running two virtual tests with the experimental parameters listed in Table 1(a) for two-step loading with L-H and H-L sequences. The two lines $\mathrm{O}-\mathrm{B}-\mathrm{C}^{\backslash}$ and $\mathrm{O}-\mathrm{A}-\mathrm{D}^{\backslash}$ represent the tests at the constant stress amplitude 432.5 $\mathrm{MPa}$ and $390 \mathrm{MPa}$. Points $\mathrm{A}$ and $\mathrm{B}$ have the same $A_{C}$. In both two-step loading tests, the application of $\sigma_{o_{1}}$ for $N_{1}$ cycles results in a behavior similar to that given in Fig. 6(a, b), i.e. the line O-A in Fig. 6(c) for the L-H sequence and the line O-B for the H-L sequence. The remaining life $N_{2}$ at $\sigma_{\sigma_{n}}$ results in summations of $\frac{N}{N_{f}}=1.25$ and 1.18 for two virtual L-H tests and 0.79 and 0.83 for two $\mathrm{H}-\mathrm{L}$ virtual tests. The corresponding experimental summations are 1.35 and 0.82 [4]. The lines B-C and A-D give the duration $N_{2}$ for the sequences $\mathrm{L}-\mathrm{H}$ and $\mathrm{H}-\mathrm{L}$ respectively. The cracking damage configuration (CDC) of the specimen at point $\mathrm{B}$ is worse than that at point $\mathrm{A}$ in terms of the number, lengths, areas and locations of existing cracks. Thus, the line $\mathrm{B}-\mathrm{C}$ is on the right of the line $\mathrm{B}-\mathrm{C}^{\prime}$ and the line A$\mathrm{D}$ is on the left of the line A-D! The results of virtual tests utilizing the same two stresses acting on specimens having the same configuration as one of the above specimens but at different ratios of $\frac{N_{1}}{N_{f_{1}}}$ with the two sequences are shown in Fig. 10 together with the corresponding two experimental data. As experimentally observed in relevant literature, $\Sigma \frac{N}{N_{f}}>1$ for the tests of L-H load sequence and $\Sigma \frac{N}{N_{f}}<1$ for the tests of H-L load sequence. Figure 11 plots the prediction of the present simulation against the corresponding experimental fatigue lifetime [4] for the repeated two-step loading block tests with the parameters listed in Table 1(b). Each test was carried out seven times with different specimen configurations. The present prediction lies generally within the scatter band acceptable amongst the fatigue community. With the stresses listed in Table 1(b), most of the pearlite surface grains experience elastic deformation in the course of the tensile and compressive parts of the high and low load cycles of the early loading blocks. The effect of the high load on the behavior of the tips advancing in those grains as a result of changing the load to the low level is not considered in the present work. There is an immediate retardation in their rate of advance $\dot{a}$ to achieve a minimum value beyond which $\dot{a}$ increases to merge with the normal behavior corresponding to the low load. Should this be considered, the present prediction will be improved.

\section{CONCLUSIONS}

The present work presents a fracture mechanics numerical model to simulate collective behavior of growing short fatigue cracks originating from the surface roughness of unnotched round specimens made of a two-phase alloy and loaded in axial stresses. The model successfully predicts the S-N curve of a ferrite-pearlite $0.4 \mathrm{C}-70 / 30$ carbon steel by making use of different specimens with surface grains randomly configured in terms of their phase, size, strength and included crack size. The model needs one single experimental endurance data point to adjust its prediction. The model predicts fatigue lifetimes in constant and variable amplitude loading with (a) two-step high-to-low and low-to-high sequences and (b) repeated two-step blocks and further recognizes the effect of surface roughness, specimen size and mean stress on fatigue lives. Comparison of the experimental fatigue lifetime and corresponding prediction shows the validity of present model. 


\section{REFERENCES}

1. Frost N. E., Marsh K. J. and Pook L. P. (1974), Metal Fatigue. Clarendon Press Oxford UK.

2. Schijve J. (2009). Fatigue of structures and Materials. $2^{\text {nd }}$ edi. Springer.

3. Meischel M., Stanzl-Tschegg S. E., Arcari, A., Iyyer, N., Apetre, N. and Phanc, N. (2015), Constant and variable-amplitude loading of aluminum alloy 7075 in the VHCF regime. Procedia Engineering, 101: 501-508

4. De Los Rios E. R., Mercer P., El-Sehily B. M. (1996), short crack growth behaviour under variable amplitude loading of shot peened surfaces. Fatigue Fract. Engng. Mater. Struct.,19: 175-184.W.

5. Zhang and Miller K. J. (1996), A study of cumulative fatigue damage under variable loading-mode conditions. Fatigue Fract. Engng. Mater. Struct. , 213: 229-239.

6. James M. N., De Los Rios E. R. (1996), Variable amplitude loading of small fatigue cracks in 6261-T6 aluminium alloy. Fatigue Fract. Engng Mater. Struct. , 4: 413-426.

7. Carpinteri, Spagnoli A., Vantador S. (2017), A review of multiaxial fatigue criteria for random variable amplitude loads. Fatigue Fract. Engng. Mater. Struct. , 40: 1007-1036.

8. Geary W. (1992), A review of some aspects of fatigue crack growth under variable amplitude loading. Int. J. Fatigue, 6: 377-386.

9. Palmgren A. (1924), Die Lebensdauer von Kugellagern, Verfahrens-techinik (Berlin), 68: 339-341.

10. Miner M. A. J. (1945), Cumulative Damage in Fatigue. Journal of Applied Mechanics, 67: A159-A164.

11. Kaechde L. (1963), Review and Analysis of Cumulative Fatigue Damage Theories, RM-3650-PR. The Rand Corporation Santa Moica.

12. Manson S. S. (1964), Interpretive report on cumulative fatigue damage in the low-cycle range. Welding Journal Research, 43: 344-352.

13. Leve H. L. (1969), Cumulative damage theories. In Metal Fatigue: Theory and Design. New York Wiley, 170-203.

14. Neill MJO. (1970), A review of some cumulative damage theories, Structures and Materials Report No. 326, Aeronautical Research Laboratories, Melbourne, Australia .

15. Dubuc J, Bi-Quoc T. and Bazergui A. (1971), Unified Theory of Cumulative Damage in Metal Fatigue, W.R.C. Bulletin, 162: 1-20.

16. Schive J. (1972), The accumulation of fatigue damage in aircraft materials and structures. AGARD-AG-157. Advisory Group for Aerospace Research and Development Paris 1972.

17. Laflen H., and Cook T. S. (1982), Equivalent damage-a critical assessment. National Aeronautics and Space Administration Contract Report. NASA CR167874. NASA.

18. Golos K. and Ellyin F. (1987), Generalization of cumulative damage criterion to multilevel cyclic loading. Theoretical and Applied Fracture Mechanics, 7: 169176.

19. Fatemi A. and Yang L. (1998), Cumulative fatigue damage and life prediction theories: a survey of the state of the art for homogeneous materials. Int. J. Fatigue, 20: 9-34. 
20. Omer and Bilir G. (1991), Experimental investigation of fatigue damage accumulation in 1100 Al Alloy. Int. J. Fatigue, 13: 3-6.

21. Lv Z., Huang H., Zhu S., Gao H. and Zuo F. (2014), A modified nonlinear fatigue damage accumulation model. International Journal of Damage Mechanics, 24: 1-14.

22. Kujawski D. and Ellyin F. (1984) A cumulative damage theory for fatigue crack initiation and propagation. Int. J. Fatigue, 6: 83-88.

23. Ghammouri M., Abbadi M., Mendez J., Belouettar S. and Zenasni M. (2011), An approach in plastic strain-controlled cumulative fatigue damage. International Journal of Fatigue, 33: 265-272.

24. Hwang W. and Han K. S. (1986), Cumulative damage models and multi-stress fatigue life prediction. Journal of Composite Material, 20: 125-153.

25. Kuroda M. (2001), Extremely low cycle fatigue life prediction based on a new cumulative fatigue damage model. International Journal of Fatigue, 24: 699703.

26. Colin J. (2009), Deformation History and Load Sequence Effects on Cumulative Fatigue Damage and Life Predictions. PhD. University of Toledo.

27. Rege K and Pavlou D. G. (2017), A one-parameter nonlinear fatigue damage accumulation model. Int. J. Fatigue, 98: 234-246.

28. Santecchia E., Hamouda A. M. S., Musharavati F., Zalnezhad E., Cabibbo M., El-Mehtedi M. and Spigarelli S. (2016), A review on fatigue life prediction methods for metals. Advances in Materials Science and Engineering, 1-26.

29. McGreevy T. E. and Socie D. F. (1999), Competing roles of microstructure and flaw size. Fatigue Fract. Engng. Mater. Struct. , 22: 495-508.

30. Wilson D., Zheng Z. and Dunne F. P. E. (2018) A microstructure-sensitive driving force for crack growth. Mechanics and Physics of Solids, 121:147-174.

31. Nadot Y. (2008), Propagation lifetime from the surface and internal defects in the ultra-high cycle fatigue regime, the Open Materials Science Journal, 2: 3539.

32. Takahashj K. and Murakami Y. (1997), Quantitative evaluation of the effect of surface roughness on fatigue strength. Engineering against Fatigue Symposium, Sheffield, UK.

33. Le Pecheur A., Clavel M., Curtit F., Rey C., Stephan J. M. and Bompard P. (2010) Influence of surface conditions on fatigue strength through the numerical simulation of microstructure. Revue de Métallurgie, 107: 477-489.

34. Anderson T. L. (2005), Fracture mechanics fundamentals and applications, $3^{\text {rd }}$ ed. CRC Press London.

35. Hussain K. (1997), Short fatigue crack behaviour and analytical models: a review. Engineering Fracture Mechanics, 4: 327-354.

36. Miller K. J. (1982), The short crack problem. Fatigue Fract. Engng. Mater. Struct. , 223-232.

37. Miller K. J. (1987), The behavior of short fatigue cracks and their initiation: part II- a general summary. Fatigue Fract. Engng. Mater. Struct. , 2: 93-113.

38. Makkonen M. (2009), Predicting the total fatigue life in metals. Int. J. Fatigue, 7: 1163-1175.

39. Gao H., Zuo F., Lü Z., Zhu S. and Huang H. (2015), Residual life prediction based on nonlinear fatigue damage accumulation model. J. Shanghai Jiaotong Univ., 4: 449-53. 
40. Manson S. S. and Halford G. R. (1981), Practical implementation of the double linear damage rule and damage curve approach for treating cumulative fatigue damage. Int. J. Fract., 2: 169-92.

41. Shang D. G. and Yao W. X. (1999), A nonlinear damage cumulative model for uniaxial fatigue. Int. J. Fatigue, 2: 187-94.

42. Mesmacque G., Garciab S., Amrouchea A. and Rubio-Gonzalez C. (2005), Sequential law in multiaxial fatigue, a new damage indicator. Int. J. Fatigue, 4: 461-7.

43. Siriwardane S., Ohgaa M., Dissanayakeb R. and Taniwaki K. (2008), Application of new damage indicator-based sequential law for remaining fatigue life estimation of railway bridges. J. Constr. Steel Res, 2: 228-37.

44. Siriwardane S., Ohga M., Kaita T. and Dissanayake R. (2009), Grain-scale plasticity based fatigue model to estimate fatigue life of bridge connections. J. Constr. Steel Res., 10: 1942-53.

45. Subramanyan S. (1976), A cumulative damage rule based on the knee point of the S-N curve. ASME J. Eng. Mater. Technol. 4: 316-21.

46. Ben-Amoz M. (2009), Cumulative damage model based on two-mode fatigue damage bounds. Materials Science and Engineering, A 504: 114-123.

47. Giancane S., Nobile R. and Panella F. W. (2010) Dattoma V. Fatigue life prediction of notched components based on a new nonlinear Continuum Damage Mechanics model. Procedia Engineering, 2: 1317-1325.

48. Aid A., Amrouche A., Bachir Bouiadjra B., Benguediab M. and G. Mesmacque (2011), Fatigue life prediction under variable loading based on a new damage mode, Materials and Design, 32, pp. 183-191.

49. Aid A., Bendouba M., Aminallah L., Amrouche A., Benseddiq N. and Benguediab M. (2012), An equivalent stress process for fatigue life estimation under multiaxial loadings based on a new on linear damage model. Materials Science and Engineering, 538: 20-27.

50. Djebli A., Aid A., Bendouba M., Amrouche A., Benguediab M. and Benseddiq N. (2013), A non-linear energy model of fatigue damage accumulation and its verification for Al-2024 aluminum alloy. Int. J. Nonlinear Mech., 51: 145-151.

51. Benkabouche S., Guechichi H., Amrouche A. and Benkhettab M. (2015), A modified nonlinear fatigue damage accumulation model under multiaxial variable amplitude loading. Int. J. Mech. Sci., 100:180-194.

52. Peng Z., Huang H. Z., Zhou J. and Li Y. F. (2018), A New Cumulative Fatigue Damage Rule Based on Dynamic Residual S-N Curve and Material Memory Concept. Metals, 456: 1-17.

53. Pavlou D. G. (2018), The theory of the S-N fatigue damage envelope: Generalization of linear, double-linear and non-linear fatigue damage models. Int. J. Fatigue, 110: 204-214.

54. Kuroda M. (2001), Extremely low cycle fatigue life prediction based on a new cumulative fatigue damage model. International Journal of Fatigue, 24: 699703.

55. Miller K. J. (1977), Zachariah KP. Cumulative damage laws for fatigue crack initiation and stage I propagation. Journal of Strain Analysis, 4: 262-270.

56. Miller K. J. and Ibrahim M. F. E. (1981), Damage accumulation during initiation and short crack growth regimes. Fatigue of Engineering Materials and Structures 1981; 3: 263-277. 
57. Navarro A. and De los Roes E. R. (1992), Fatigue crack propagation modeling by successive blocking of dislocations. Proc. R. Soc. , A437: 375-390.

58. Hobson P. D., Brown M. W. and de los Rios E. R. (1986), Two phases of short crack growth in a medium carbon steel. In. The Behavior of Short Fatigue Cracks (Edited by K. J. Miller and E. R. de los Rios), pp. 441-459, EGF Pub1. No.1. Mech. Engng. Pub1. Inst. Mech. Engrs. London.

59. Zhu C. (1994), A model for small fatigue crack growth. Fatigue Fract. Engng. Mater. Struct. , 17: 69-73.

60. Angelova D. and Akid R. (1998), A note on modeling short fatigue cracks behavior. Fatigue Fract. Engng. Mater. Struct. , 21: 771-779.

61. Newmamn J. C. and Ji. (1994) A review of modeling small-crack behaviour and fatigue-life predictions for aluminium alloys. Fatigue Fract. Engng. Mater. Struct. , 17: 429-439.

62. Hammouda M. M. I. and Sallam H. E. (1993), An elastic-plastic finite element simulation of crack tip deformation in fatigue. Presented at Kiev ICF8.

63. Hammouda M. M. I., E.1-Sehily B. M. and de los Rios E. R. (1995) The significance of crack tip deformation for short and long fatigue cracks. Fatigue Fract. Engng. Mater. Struct. , 19: 475-484.

64. Bozic Z., Milkota M. and Schmauder S. (2011), Application the $\Delta \mathrm{K}_{z} \Delta \mathrm{J}$ and $\triangle \mathrm{CTOD}$ parameters in fatigue crack growth modelling. Technical Gazette, 3: 459-466.

65. XI X. J. and De Los Rios E. R. (1994), Interactive effect of two coplanar cracks on plastic yielding and coalescence. Fatigue Fract. Engng. Mater. Struct. , 9: 1045-1056.

66. Soboyejo W. O., kishimoto K., Smith R. A. and Knott J. F. (1989) A study of the interaction and coalescence of two coplanar fatigue cracks in bending. Fatigue Fract. Engng. Mater. Struct. , 3: 167-174.

67. Seah T. T. (2018), Qian X. An interaction factor to estimate the overconstraining effect in plates with co-planar cracks. Engineering Fracture Mechanics, 199: 13-28.

68. Angelova D., Yordanova R. and Lazarova T. (2014), On factors influencing fatigue process in steel 3161 used in hydrogen energy technologies. Chemical Technology and Metallurgy, 49: 29-34.

69. Wang Y. Z., Atkinson J. D., Akid R. and Parkins R. N. (1996), Crack interaction, coalescence and mixed mode fracture mechanics. Fatigue Fract. Engng. Mater. Struct. , 19: 427-439.

70. Hara P. O., Duarte C. A. and Eason T. (2016), A two scale generalized finite element method for interaction and coalescence of multiple crack surfaces. Eng. Fract. Mech., 163: 274-302.

71. Basquin O. H. (1910), The exponential law of endurance tests. Proceedings of the American Society for Testing and Materials, 10: 625-630. 

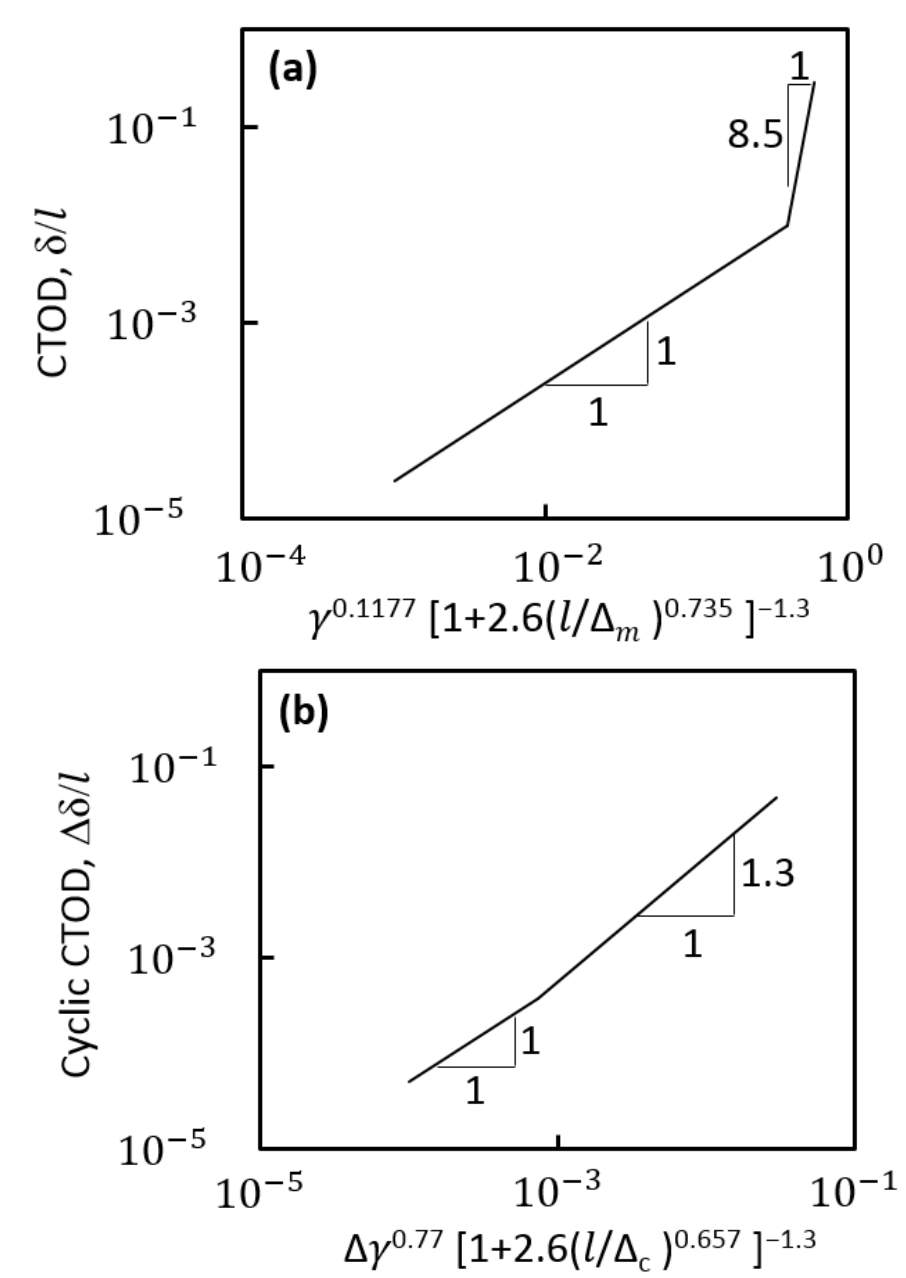

Fig. 1 Crack tip opening displacement (a) maximum extent fitted to crack length, $l$, monotonic crack tip plastic zone size, $\Delta n_{m}$ and the corresponding average shear strain within $\Delta_{m} \gamma_{r}$ (b) cyclic extent fitted to crack length, $L$, cyclic crack tip plastic zone size, $\Delta_{\varepsilon}$ and the corresponding average shear strain range within $\Delta_{m^{\prime}} \Delta \gamma$

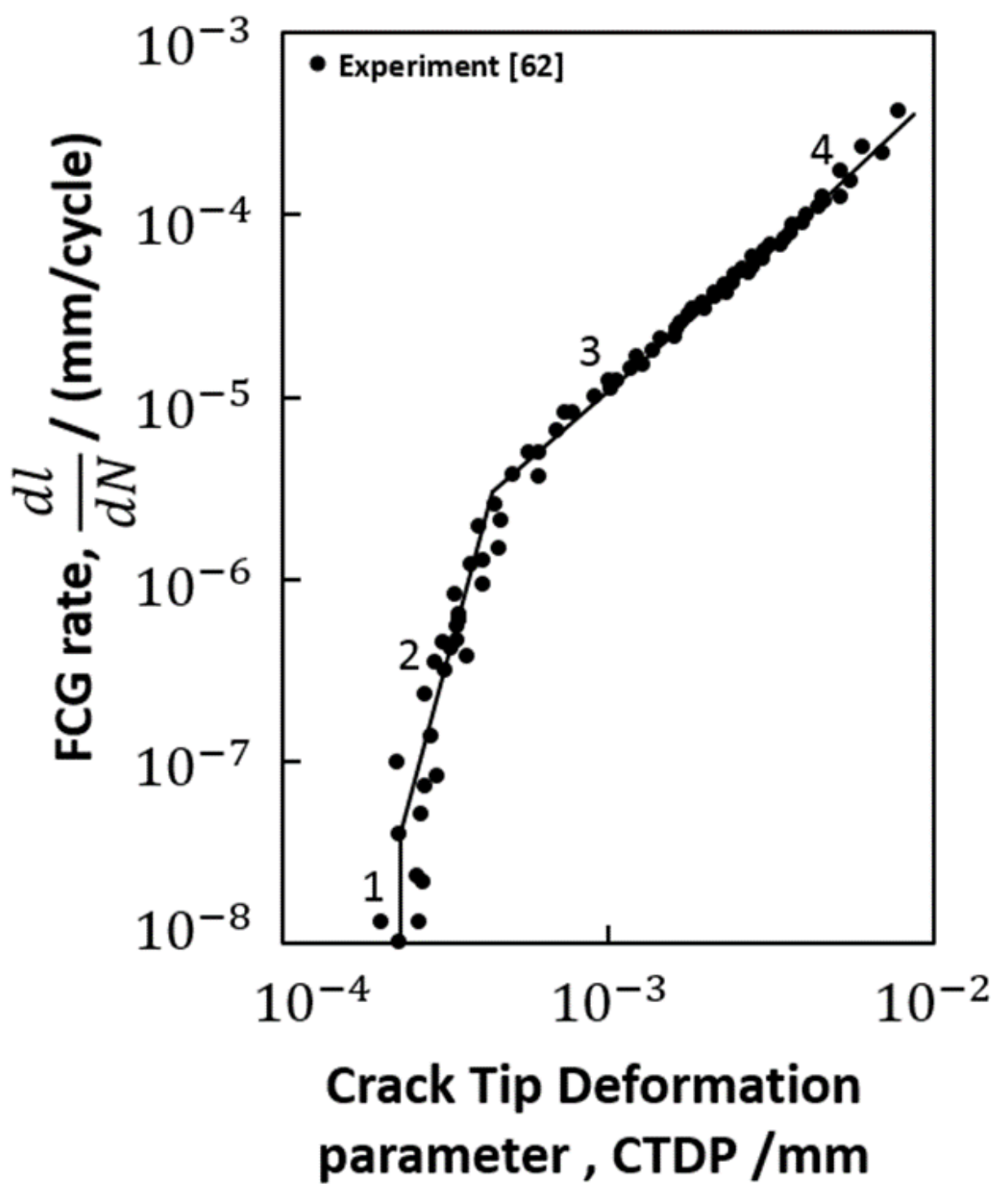

Fig. 2 Fatigue crack growth behavior in the present model. 


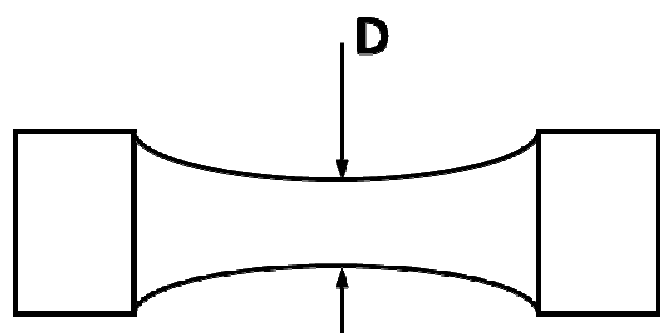

(a)

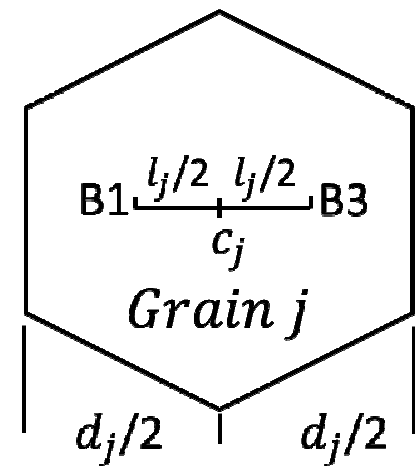

(c)

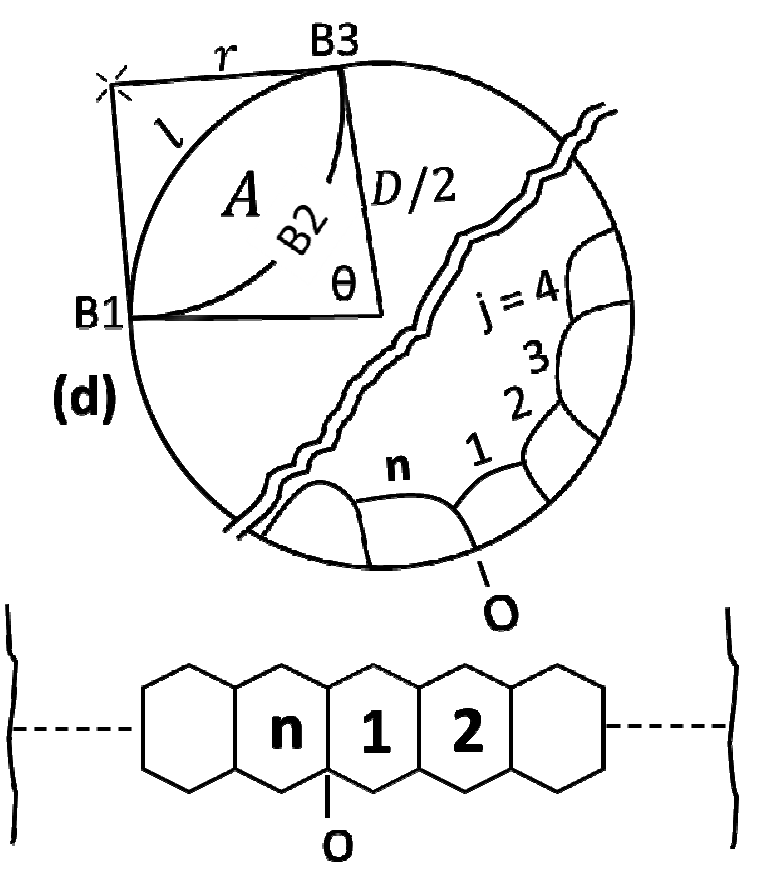

(b)

Fig.3 (a) Geometry of the considered specimen, (b) $n$ grains along the circumference of the minimum cross section, (c) a grain $j$ with a center $c_{j}$ and a size $d_{j}$ containing a crack on the surface of a length $l_{j}$, (d) a

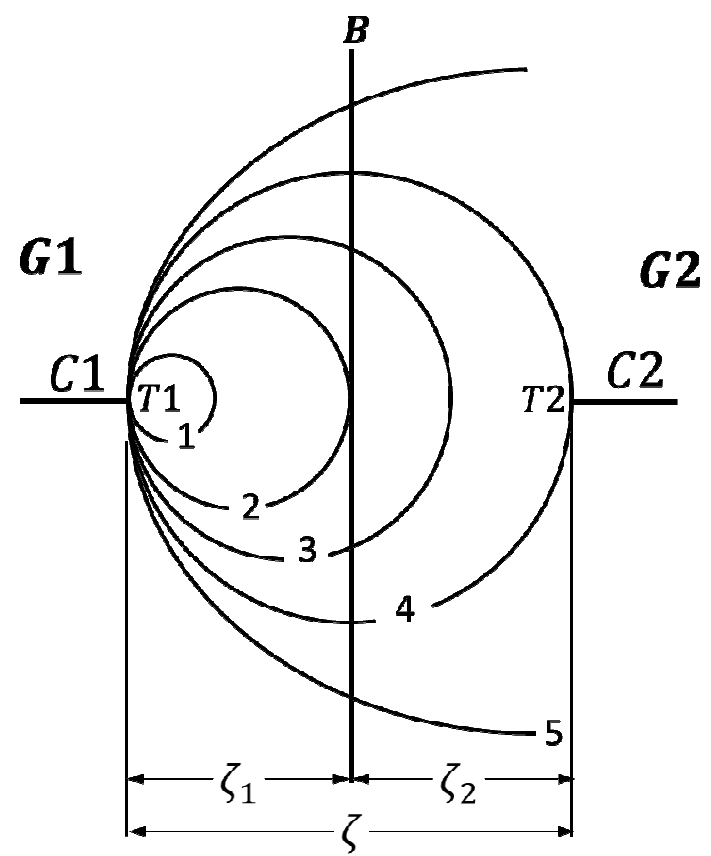

(a)

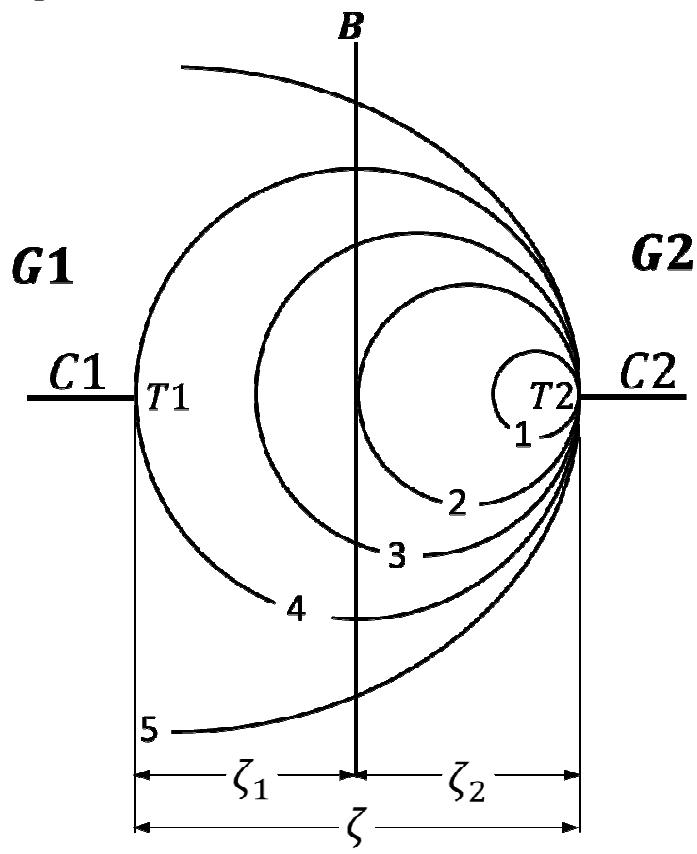

(b)

Fig. 4 Possibilities of plasticity extents ahead of two opposing tips, $T_{1}$ and $T_{2}$, of two cracks, $C_{1}$ and $C_{2}$, located in two neighboring surface grains, $G_{1}$ and $G_{2}$. 


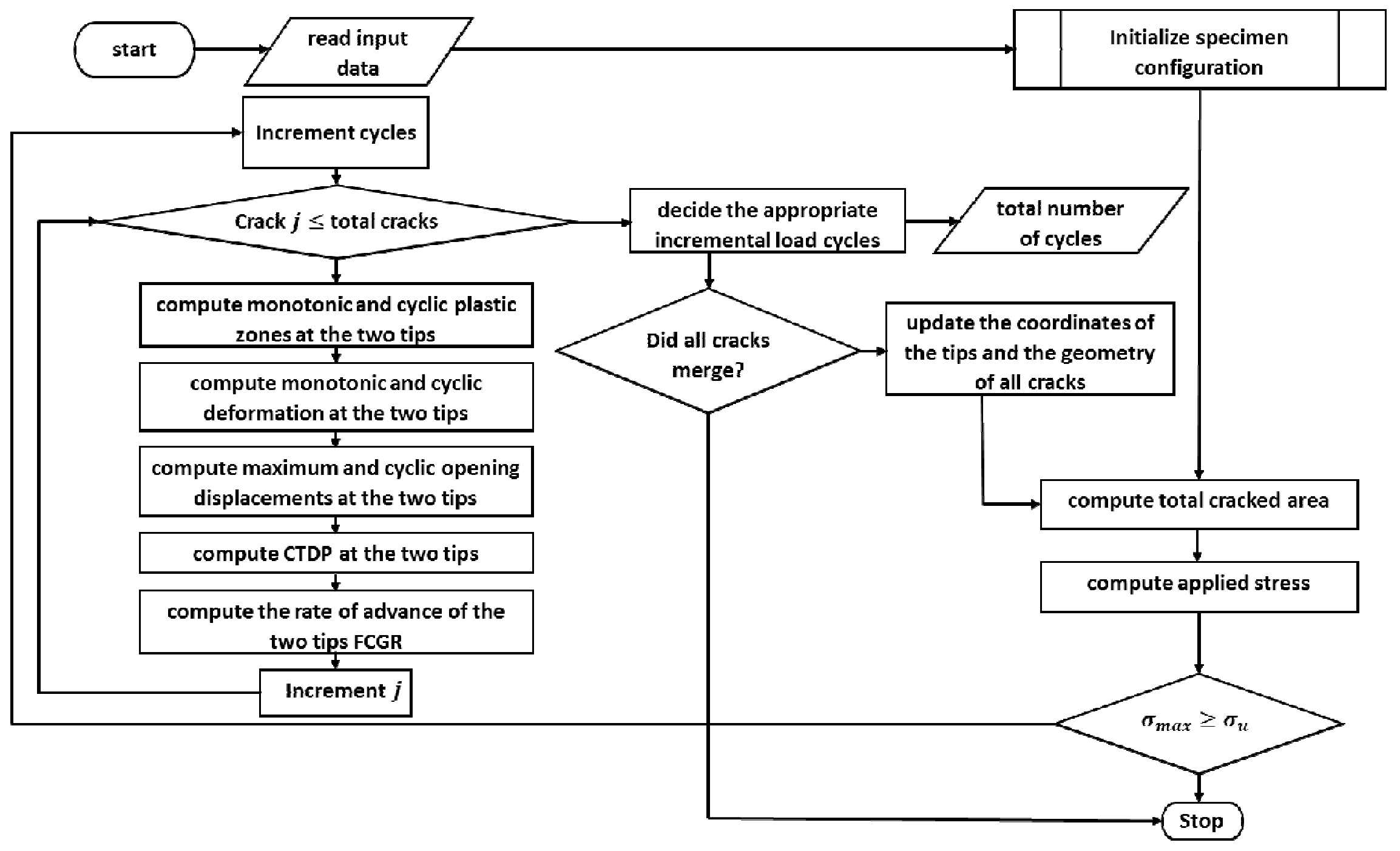

Fig. 5 Flow chart of the computer program developed in the present work. 

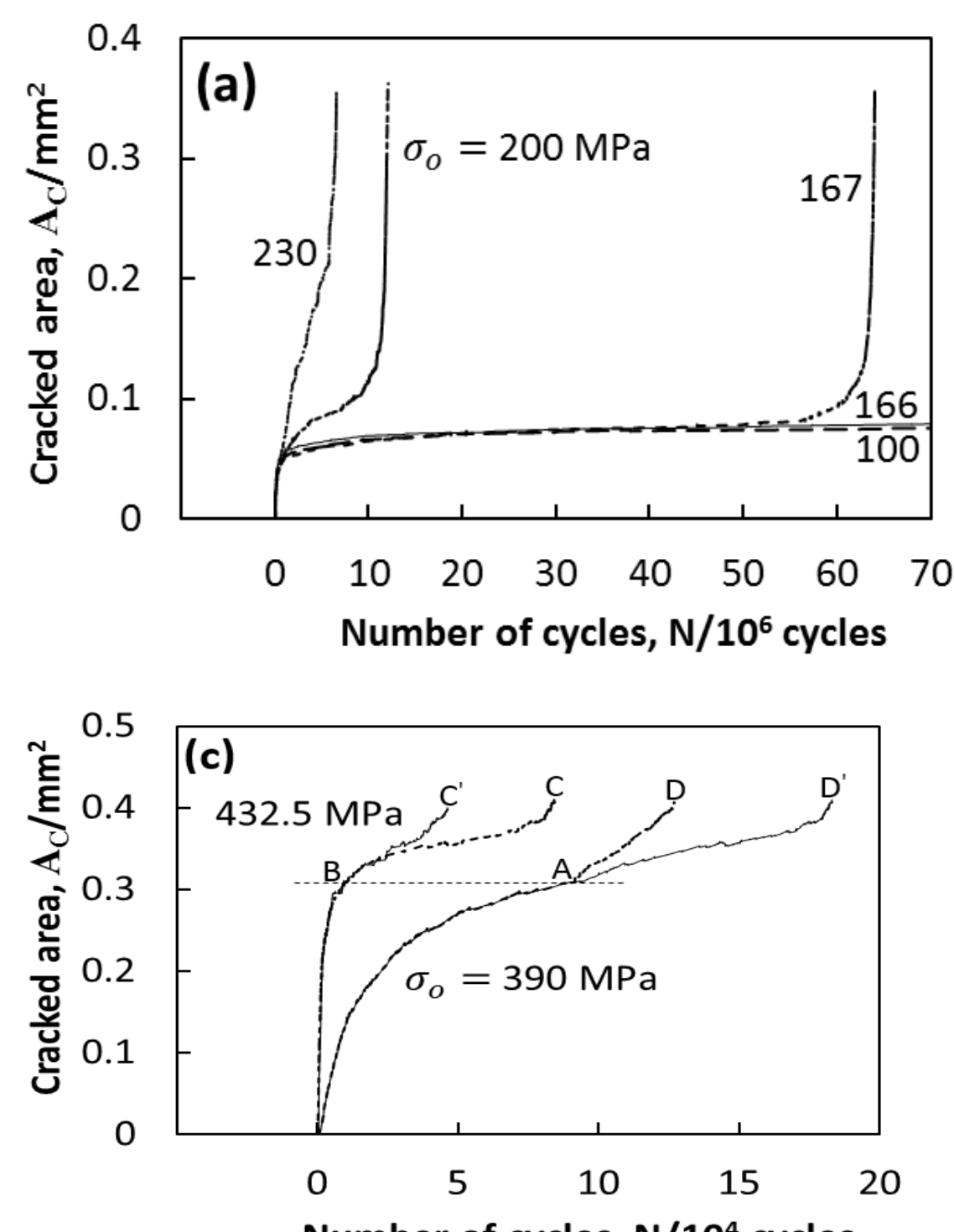

Number of cycles, $\mathrm{N} / 10^{4}$ cycles

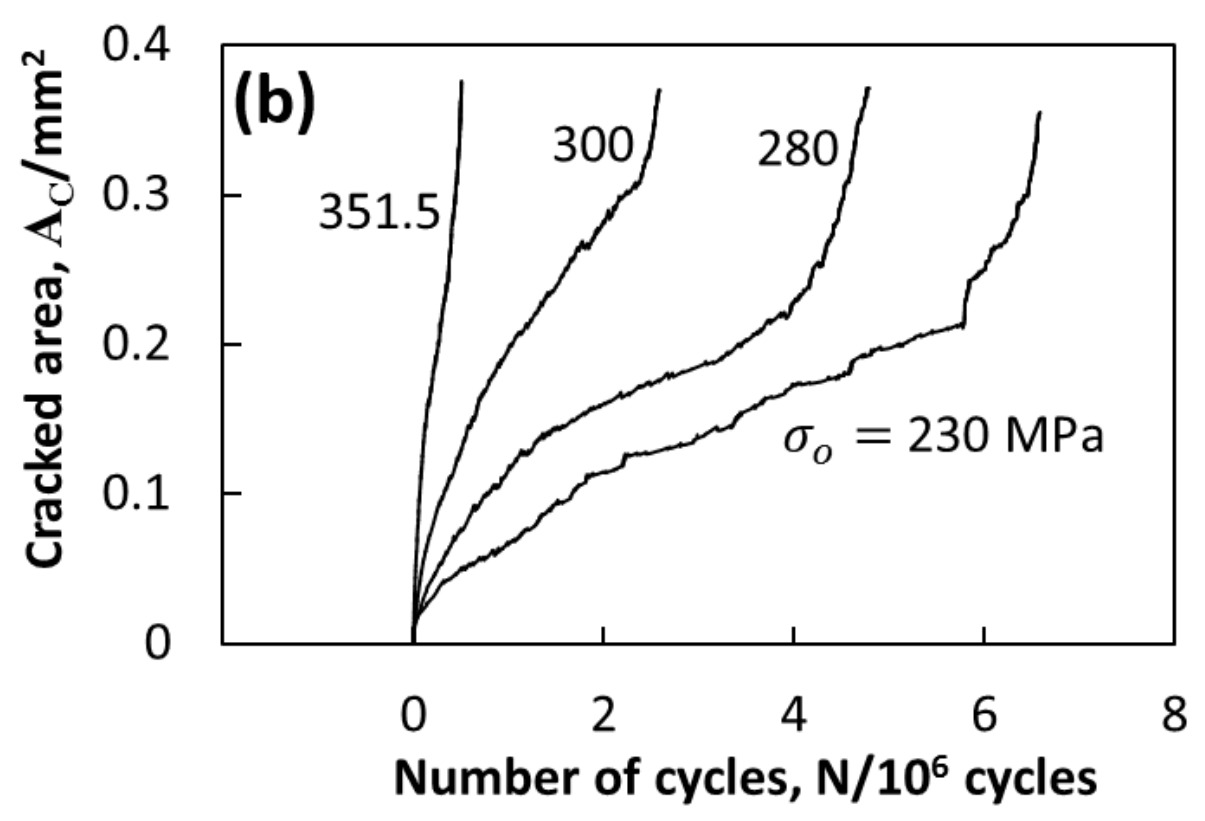

Fig. 6 Fatigue crack growth behavior assessed by the present model (a, b) at some stress amplitude and (c) for H-L and L-H tests. 
FATIGUE LIFE PREDICTION OF UN-NOTCHED ROUND SPECIMENS BASED ON CRACKING SIMULATION
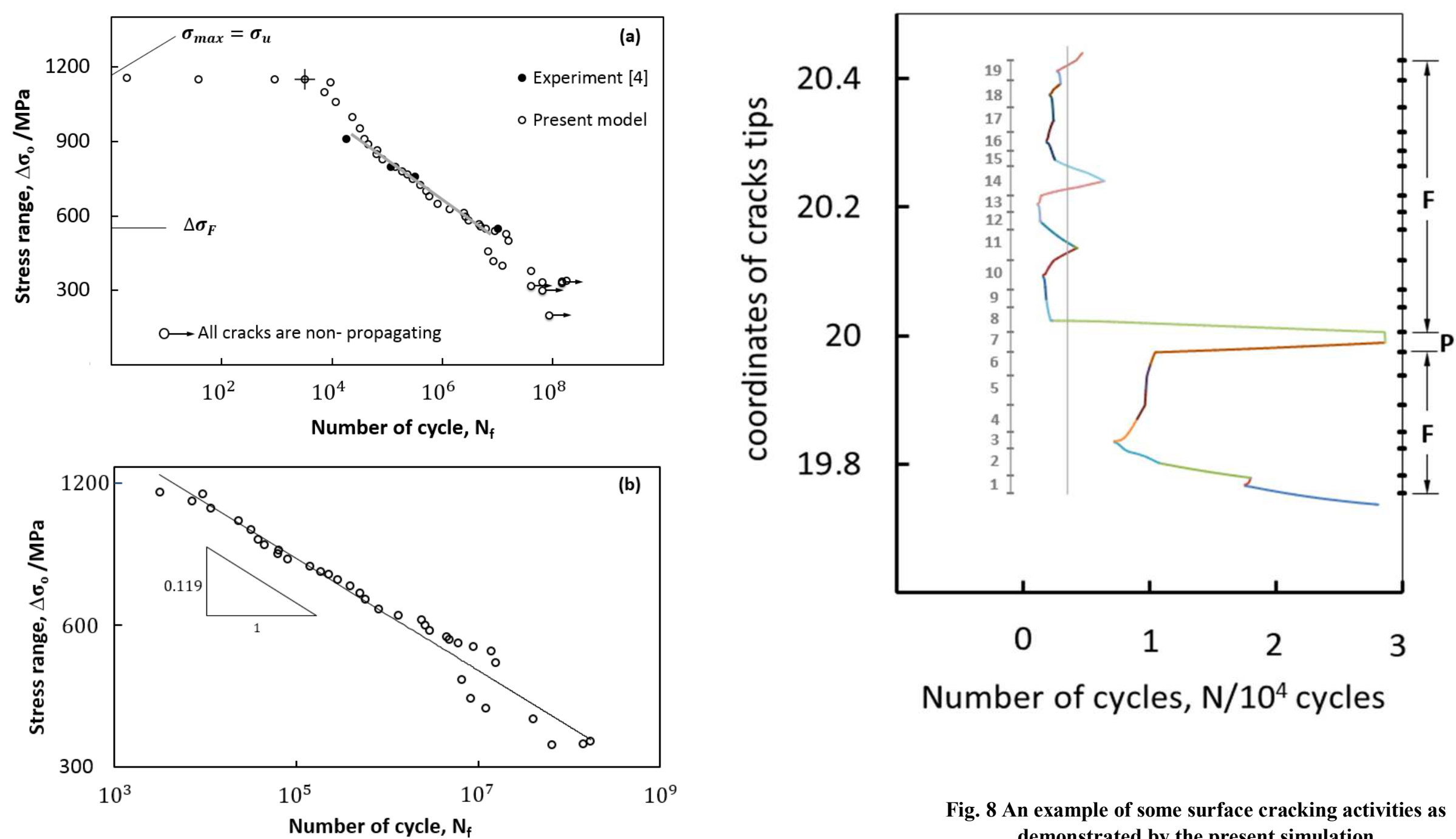

Fig. 7 Fatigue lifetime predicted by the present cracking simulation; (a) Prediction versus experiment, the grey line fits the experimental data; (b) Predicted HCF life re-plotted on log-log scales 
FATIGUE LIFE PREDICTION OF UN-NOTCHED ROUND SPECIMENS BASED ON CRACKING SIMULATION
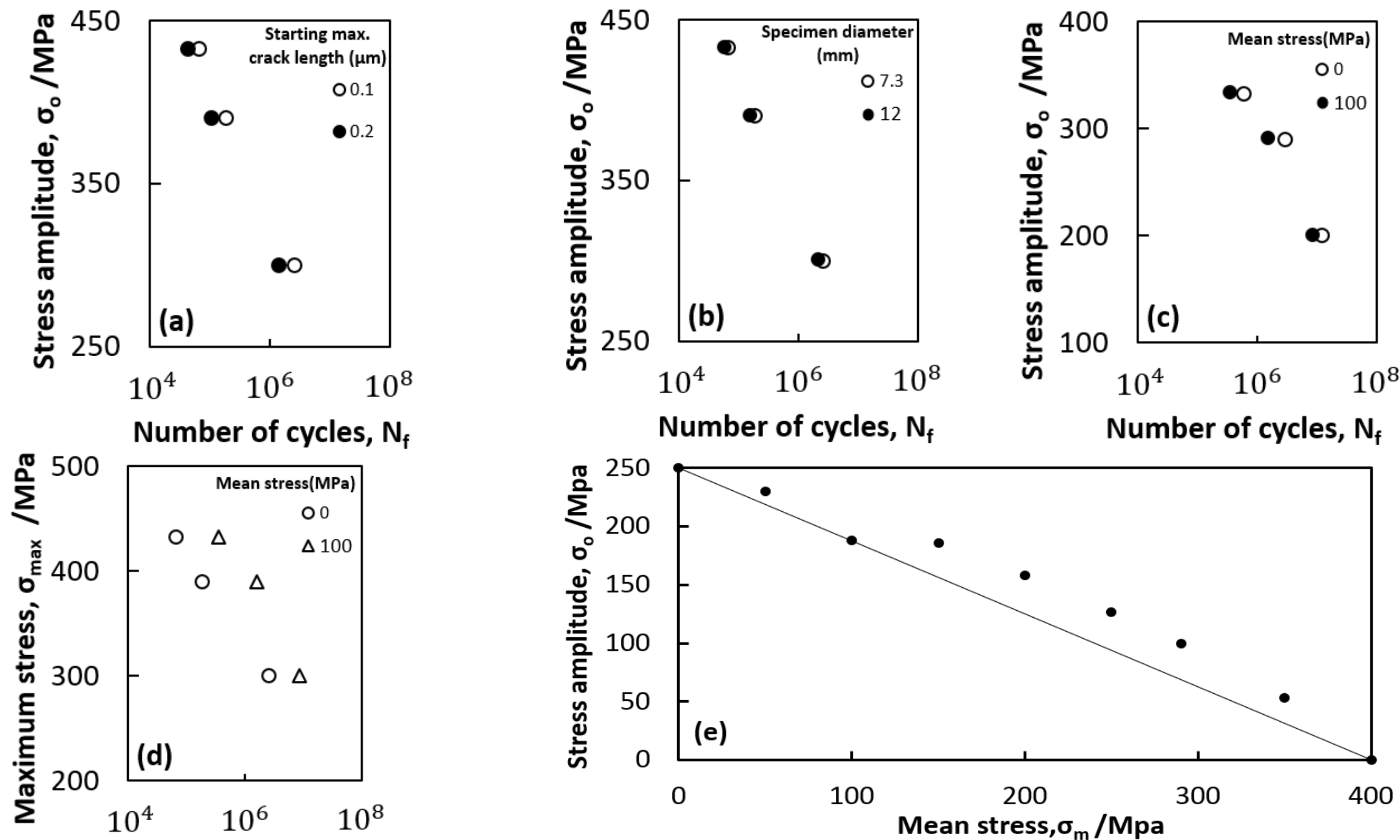

Number of cycles, $\mathrm{N}_{\mathrm{f}}$

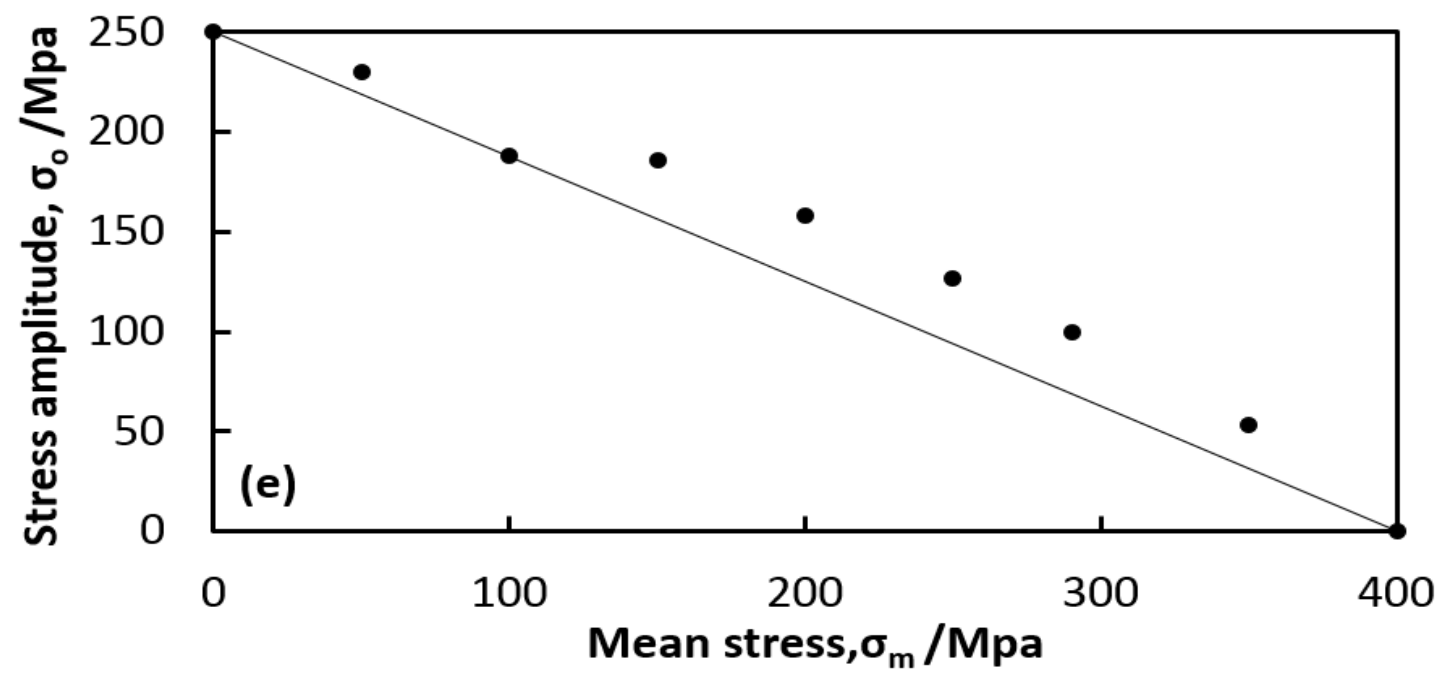

Number of cycles, $\mathrm{N}_{\mathrm{f}}$

Fig. 9 Effect of (a) surface roughness; (b) specimen size; (c, d) mean stress on fatigue lifetime and(e) $10^{7}$-based 


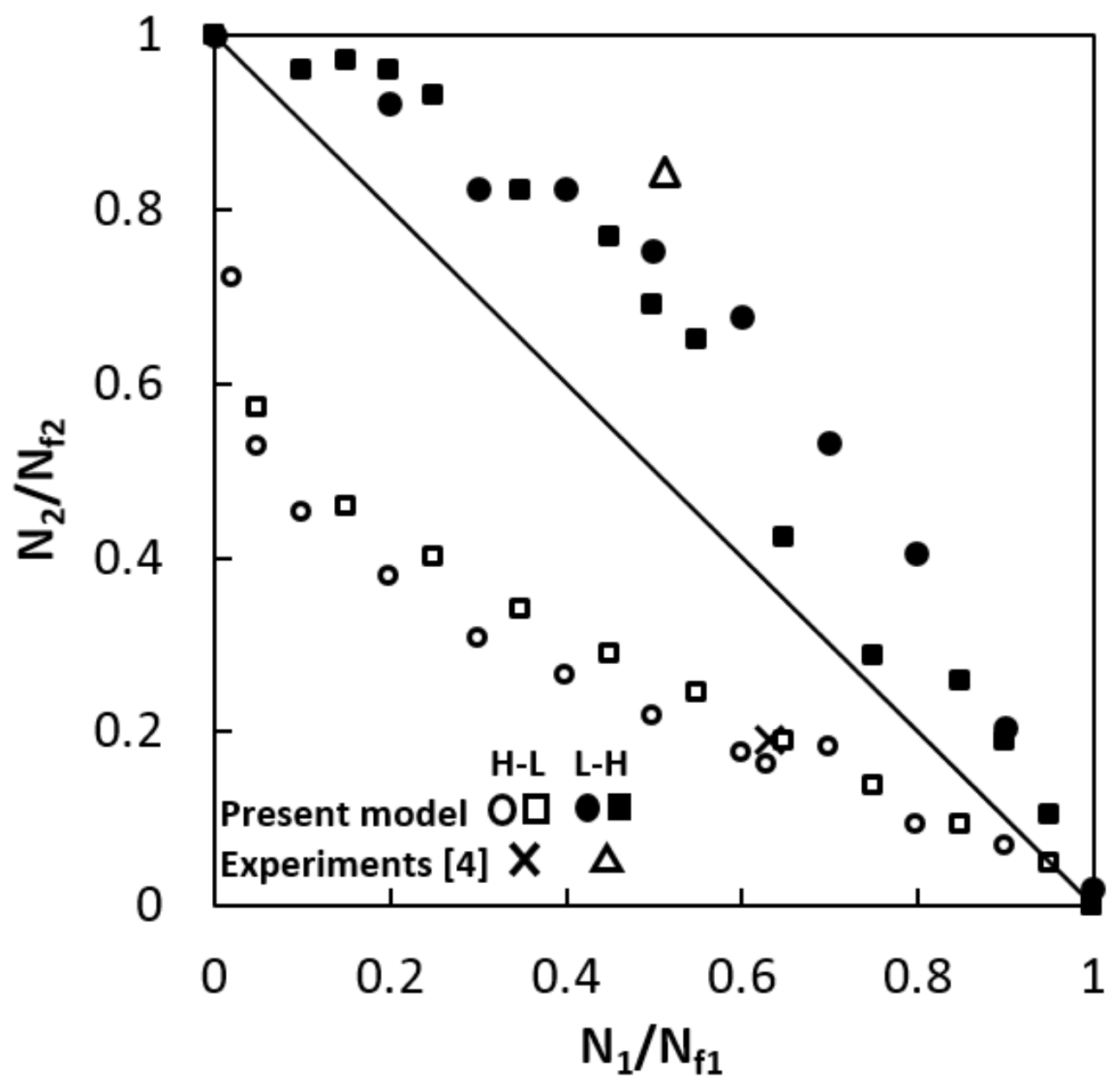

Figure 10 Present prediction results of two-step cumulative fatigue loading tests having $\mathrm{L}-\mathrm{H}$ and $\mathrm{H}-\mathrm{L}$ sequences and available experimental data with the two stress amplitudes of $390 \mathrm{MPa}$ and $432.5 \mathrm{MPa}$ and $\mathrm{R}=-1$

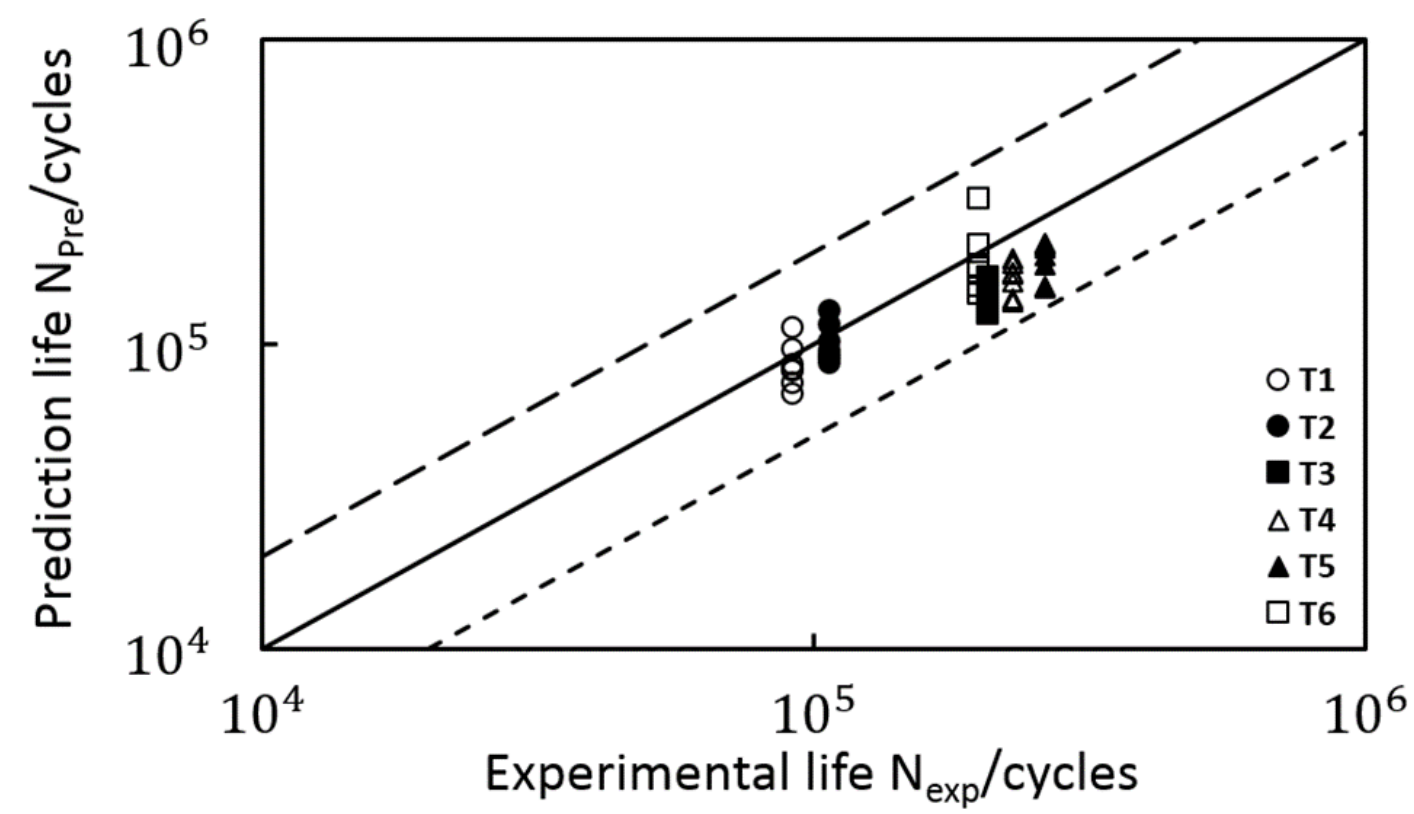

Fig. 11 Prediction of the present simulation against the corresponding experimental fatigue lifetime [4] for the repeated two-step loading block tests with the parameters listed in Table 1(b); Each test was carried out seven times with different specimen configurations 
Table 1 Experimental parameters of (a) two sets of two-step cumulative fatigue damage; (b) repeated twostep loading blocks

(a)

\begin{tabular}{|c|c|c|c|c|c|c|c|c|}
\hline \multirow[b]{2}{*}{ Test } & \multirow[b]{2}{*}{ Type } & \multicolumn{3}{|c|}{$1^{\text {st }}$ Loading level } & \multicolumn{3}{|c|}{$2^{\text {nd }}$ Loading level } & \multirow{2}{*}{$\begin{array}{c}\text { Cycles to } \\
\text { fracture } \\
\text { Nf }\end{array}$} \\
\hline & & $\begin{array}{c}\sigma_{01} \\
\mathrm{MPa}\end{array}$ & $\mathrm{NF}_{1}$ & N1 & $\begin{array}{c}\sigma_{\mathrm{O} 2} \\
\mathrm{MPa}\end{array}$ & $\mathbf{N F}_{2}$ & N2 & \\
\hline 1 & $\mathrm{H}-\mathrm{L}$ & 432.5 & 39665 & 25002 & 390 & 194968 & 37171 & 62173 \\
\hline 2 & L-H & 390 & 194968 & 100005 & 432.5 & 39665 & $33411^{`}$ & 133416 \\
\hline
\end{tabular}

(b)

\begin{tabular}{|c|c|c|c|c|c|c|c|}
\hline \multicolumn{3}{|c|}{$1^{\text {st }}$ Loading level } & \multicolumn{3}{|c|}{$2^{\text {nd }}$ Loading level } & \multirow{2}{*}{$\begin{array}{c}\text { Cycles } \\
\text { to } \\
\text { fracture } \\
\mathrm{Nf}\end{array}$} & \multirow[b]{2}{*}{ Tests } \\
\hline $\begin{array}{l}\sigma_{01} \\
\mathrm{MPa}\end{array}$ & $\begin{array}{c}\text { Blocks } \\
\text { B1 }\end{array}$ & $\begin{array}{c}\text { Cycles/block } \\
\text { N1 }\end{array}$ & $\begin{array}{l}\sigma_{\mathrm{O} 2} \\
\mathrm{MPa}\end{array}$ & $\begin{array}{c}\text { Blocks } \\
\text { B2 }\end{array}$ & $\begin{array}{c}\text { Cycles/block } \\
\text { N2 }\end{array}$ & & \\
\hline \multirow{3}{*}{425} & 16 & \multirow{3}{*}{1000} & 415 & 15 & 5000 & 91780 & T1 \\
\hline & 10 & & 400 & 10 & 10000 & 107319 & T2 \\
\hline & 10 & & 385 & 10 & 20000 & 207811 & T3 \\
\hline \multirow{3}{*}{387.5} & 14 & \multirow{3}{*}{15000} & \multirow{3}{*}{425} & 14 & 1 & 229957 & T4 \\
\hline & 16 & & & 16 & 10 & 262769 & T5 \\
\hline & 13 & & & 13 & 100 & 199179 & T6 \\
\hline
\end{tabular}

